\title{
ANALISA PENGARUH CAMPURAN BIOETANOL DALAM PREMIUM PADA SEPEDA MOTOR
}

\author{
Sumantri W. Praja, ST, M.Sc \\ Dosen STTD \\ Jl. Raya Setu No. 89, Bekasi \\ Telp./Fax : (021) 8254640 \\ Ir. Juliaman P., M.Si \\ Dosen STTD \\ Jl. Raya Setu No. 89, Bekasi \\ Telp./Fax : (021) 8254640
}

\author{
Ricko Yudhanta, ST, M.Sc \\ Dosen STTD \\ Jl. Raya Setu No. 89, Bekasi \\ Telp./Fax : (021) 8254640 \\ DR. Ir. Djajadi, MM \\ Dosen STTD \\ Jl. Raya Setu No. 89, Bekasi \\ Telp./Fax : (021) 8254640
}

\begin{abstract}
Fuel scarcity is a common and common problem in the country of Indonesia. This problem is one of the problems that greatly affects the community, especially the people who use motorbikes, because fuel oil is one of the things that needs to be used for vehicles. Energy consumption in Indonesia is almost half the need for fossil fuels, such as the industrial sector, transportation sector, household sector and commercial sector. Indonesia needs the development of renewable energy sources as an alternative energy mixture of fuels to save oil use. Actually in Indonesia there are various abundant renewable energy sources, such as biodiesel from Jatropha curcas, palm oil and soybeans for diesel engines. Or methanol and ethanol from biomass, sugar cane, corn, which can be used as a substitute for gasoline. The function of adding bioethanol to fuel is as an octane booster, meaning that it can increase the octane number with a positive impact on fuel efficiency and improve combustion and minimize air pollution. The addition of bioethanol at premium can produce better exhaust emissions (lower $\mathrm{CO}$ and $H C$ content) than emissions produced by pure premium fuel $\left(E_{0}\right)$. This is indicated by research data on the results of testing the content of CO emissions in vol\%, and the results of testing the content of $\mathrm{HC}$ emissions in ppm vol. The lower CO content of the use of pure premium fuel $\left(E_{0}\right)$ is produced by the use of $E_{5}$ to $E_{20}$ fuels. The lower HC content from the use of pure premium fuel $\left(E_{0}\right)$ is produced by the use of $E_{5}$ to $E_{10}$ fuel. The addition of bioethanol also affects lambda values. At the same engine speed, the lambda value increases with the amount of bioethanol concentration in the fuel, but is getting closer to the ideal at higher engine speed. This happens in every variation of fuel. After conducting a series of research tests, the composition of the most effective addition of bioethanol to produce better emissions (low CO and HC) is in the composition of 10\%. This is because the $E_{10}$ fuel produces $C O$ which is lower than $E_{5}$ and produces the lowest $H C$ level of the other fuel. Lambda value on $E_{10}$ fuel still tends to be close to ideal than $E_{15}$ fuel.
\end{abstract}

Keywords : Motorcycle, Fuel, Testing, Premium, Bioethanol, Emissions, Air Pollution, Exhaust Gas, Lambda, CO, HC 


\begin{abstract}
ABSTRAKSI
Kelangkaan bahan bakar merupakan masalah yang sering terjadi dan umum di Negara Indonesia. Masalah ini adalah salah satu masalah yang sangat berdampak pada masyarakat, terutama masyarakat yang menggunakan sepeda motor, karena bahan bakar minyak adalah salah satu hal yang perlu digunakan bagi kendaraan. Konsumsi energi di Indonesia hampir setengahnya membutuhan bahan bakar fosil, seperti sektor industri, sektor transportasi, sektor rumah tangga dan sektor komersial. Indonesia memerlukan pengembangan sumber energi terbarukan sebagai energi alternatif campuran bahan bakar untuk menghemat penggunaan minyak. Sebenarnya di Indonesia terdapat berbagai sumber energi terbarukan yang melimpah, sepeti biodiesel dari tanaman jarak pagar, kelapa sawit maupun kedelai untuk mesin diesel. Atau methanol dan ethanol dari biomassa, tebu, jagung, yang bisa dipergunakan sebagai pengganti bensin. Fungsi penambahan bioetanol pada bahan bakar adalah sebagai octane booster, artinya mampu menaikkan angka oktan dengan dampak positif pada efisiensi bahan bakar dan menyempurnakan pembakaran dan meminimalkan pencemaran udara. Penambahan bioetanol pada premium mampu menghasilkan emisi gas buang yang lebih baik (kandungan $\mathrm{CO}$ dan $\mathrm{HC}$ yang lebih rendah) daripada emisi yang dihasilkan oleh bahan bakar premium murni $\left(\mathrm{E}_{0}\right)$. Hal ini ditunjukkan oleh data penelitian tentang hasil pengujian kandungan emisi $\mathrm{CO}$ dalam \% vol, dan hasil pengujian kandungan emisi $\mathrm{HC}$ dalam ppm vol. Kandungan $\mathrm{CO}$ yang lebih rendah dari penggunaan bahan bakar premium murni $\left(\mathrm{E}_{0}\right)$ dihasilkan oleh penggunaan bahan bakar $E_{5}$ hingga $E_{20}$. Kandungan $H C$ yang lebih rendah dari penggunaan bahan bakar premium murni $\left(\mathrm{E}_{0}\right)$ dihasilkan oleh penggunaan bahan bakar $\mathrm{E}_{5}$ hingga $\mathrm{E}_{10}$. Penambahan bioetanol juga berdampak pada nilai lambda. Pada putaran mesin yang sama, nilai lambda mengalami peningkatan seiring jumlah konsentrasi bioetanol dalam bahan bakar, namun semakin mendekati ideal pada putaran mesin yang semakin tinggi. Hal tersebut terjadi pada setiap variasi bahan bakar. Setelah melakukan serangkaian uji penelitian, maka komposisi penambahan bioetanol yang paling efektif menghasilkan emisi yang lebih baik (CO dan $\mathrm{HC}$ rendah) adalah pada komposisi 10\%. Hal ini dikarenakan bahan bakar $\mathrm{E}_{10}$ menghasilkan $\mathrm{CO}$ yang lebih rendah dari $\mathrm{E}_{5}$ dan menghasilkan kadar $\mathrm{HC}$ yang paling rendah dari bahan bakar yang lain. Nilai lambda pada bahan bakar $\mathrm{E}_{10}$ masih cenderung mendekati ideal dari pada bahan bakar $\mathrm{E}_{15}$.
\end{abstract}

Kata kunci : Sepeda Motor, Bahan Bakar, Pengujian, Premium, Bioetanol, Emisi, Pencemaran Udara, Gas Buang, Lambda, CO, HC 


\section{PENDAHULUAN}

\section{Latar Belakang}

Kelangkaan bahan bakar merupakan masalah yang sering terjadi dan umum di Negara Indonesia. Masalah ini adalah salah satu masalah yang sangat berdampak pada masyarakat, terutama masyarakat yang berkendara baik roda satu maupun roda dua karena bahan bakar minyak adalah salah satu hal yang perlu digunakan bagi kendaraan. Konsumsi energi di Indonesia hampir setengahnya membutuhan bahan bakar fosil, seperti sektor industri, sektor transportasi, sektor rumah tangga dan sektor komersial.

Indonesia memerlukan pengembangan sumber energi terbarukan sebagai energi alternatif campuran bahan bakar untuk menghemat penggunaan minyak. Sebenarnya di Indonesia terdapat berbagai sumber energi terbarukan yang melimpah, sepeti biodiesel dari tanaman jarak pagar, kelapa sawit maupun kedelai untuk mesin diesel. Atau methanol dan ethanol dari biomassa, tebu, jagung, dll yang bisa dipergunakan sebagai pengganti bensin.

Bioetanol atau yang sering disebut alkohol, merupakan bahan bakar yang berasal dari biomassa. Biomassa adalah bahan organik yang dihasilkan melalui proses fotosintesis baik berupa produk maupun buangan. Biomassa merupakan sumber daya yang terbaharui karena jumlahnya yang berlimpah, berkesinambungan dan berpotensi sebagai alternatif bahan bakar untuk menggantikan bahan bakar fosil. Fungsi penambahan bioetanol pada bahan bakar adalah sebagai octane booster, artinya mampu menaikkan angka oktan dengan dampak positif pada efisiensi bahan bakar dan mesin oxygenating agent, yakni mengandung oksigen sehingga menyempurnakan pembakaran dan meminimalkan pencemaran udara; dan fuel extender, yaitu menghemat bahan bakar fosil.

Berdasarkan permasalahan di atas, maka penulis akan mengadakan penelitian yang diharapkan dapat mengatasi hal tersebut yang tertuang dalam laporan "Analisa Pengaruh Campuran Bioetanol Dalam Premium Pada Sepeda Motor". 


\section{METODOLOGI PENELITIAN}

\section{Metode Pengumpulan Data}

Dalam melaksanakan penelitian, untuk memperoleh hasil yang baik maka diperlukan sejumlah data pendukung agar dapat dilakukan analisa data. Data yang dibutuhkan untuk penelitian ini berdasarkan dari data sekunder dan data primer.

Pengumpulan data dalam penelitian ini dilakukan melalui metode yang digunakan adalah dengan observasi lapangan dengan melakukan uji coba menggunakan sampel yang telah ditentukan yaitu kendaraan bermotor yang akan digunakan sebagai objek penelitian ini.

\section{Metode Penelitian}

Penelitian ini adalah penelitian eksperimen yang dilaksanakan di Laboratorium Pengujian dan Kontrol Kendaraan Bermotor, bertujuan untuk mengetahui sebab akibat yang muncul berdasarkan perubahan perlakuan peneliti. Perubahan perlakuan tersebut adalah pengaruh pemakaian bahan bakar $\mathrm{E}_{0}, \mathrm{E}_{5}, \mathrm{E}_{10}$, $\mathrm{E}_{15}$, dan $\mathrm{E}_{20}$ terhadap perubahan lambda, $\mathrm{CO}, \mathrm{HC}, \mathrm{CO}_{2}$, serta $\mathrm{O}_{2}$ pada sepeda motor 4 tak yang diukur menggunakan alat uji emisi gas buang Capelec 3201.

\section{Sampel Penelitian}

Dalam penelitian ini variabel bebas meliputi bahan bakar premium murni $\left(\mathrm{E}_{0}\right)$, campuran bioetanol $5 \%+$ premium $95 \%\left(\mathrm{E}_{5}\right)$, campuran bioetanol $10 \%+$ premium $90 \%\left(\mathrm{E}_{10}\right)$, campuran bioetanol $15 \%+$ premium $85 \%\left(\mathrm{E}_{15}\right)$, dan campuran bioetanol $20 \%+$ premium $80 \%\left(\mathrm{E}_{20}\right)$.

Variabel terikat meliputi lambda dan kandungan emisi gas buang pada sepeda motor 4 Tak 1 Silinder. Pada penelitian ini variabel kontrol meliputi : a) Sepeda motor 4 Tak 1 Silinder; b) Temperatur oli mesin 60-80 oC (temperatur kerja mesin); c) Variasi putaran mesin idle di rentang $1500 \mathrm{rpm}, 2000 \mathrm{rpm}$ dan $2500 \mathrm{rpm}$. 


\section{Teknik Analisis Data}

Teknik analisis data yang digunakan dalam penelitian ini menggunakan metode statistika deskriptif. Menurut Sugiyono (2009:147), statistik deskriptif adalah statistik yang berfungsi untuk mendeskripsikan atau memberi gambaran terhadap data yang telah terkumpul sebagaimana adanya tanpa bermaksud membuat kesimpulan yang berlaku untuk umum.

\section{Alat dan Bahan}

1. Alat-alat yang digunakan dalam penelitian ini adalah sebagai berikut:

a. Burret tester (Gelas Ukur), alat untuk menampung bahan bakar.

b. Stopwatch, untuk mengukur waktu.

c. Tachometer, untuk mengukur putaran mesin.

d. Blower, untuk menjaga suhu kerja mesin.

e. Emisi tester CAPELEC 3201, untuk menguji kandungan emisi gas buang. Dengan spesifikasi alat:

1) Power supply : : $115-230 \mathrm{~V} 1,5 \mathrm{~A}$

2) Max consumption : $70 \mathrm{~W}$

3) Measurement range : 0 to $99.9 \%$ res. 0,1

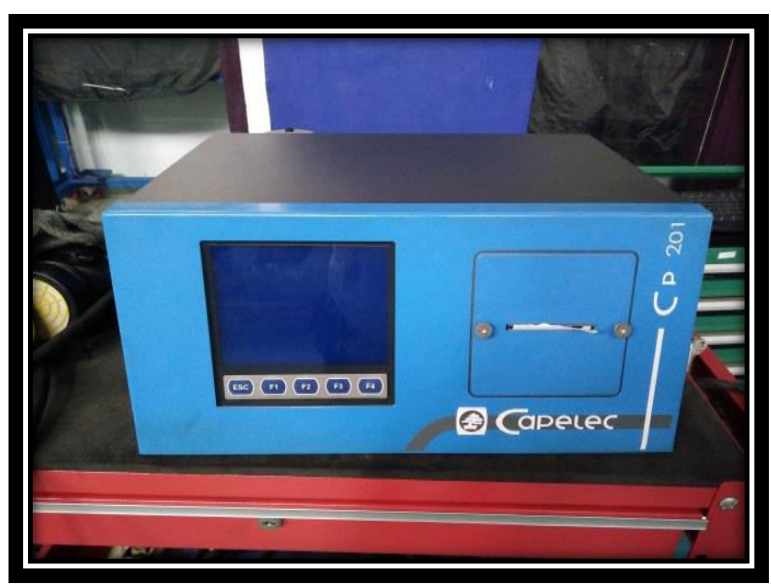

Gambar 1. Alat Uji Emisi Gas Buang 
2. Bahan-bahan yang digunakan dalam penelitian ini adalah sebagai berikut:

a. Sepeda motor Honda Vario 2011, dengan spesifikasi :

1) Tipe mesin :4 Langkah SOHC

2) Sistem pendinginan : Pendinginan dengan cairan

3) Diameter $x$ Langkah :50 x $55 \mathrm{~cm}$

4) Volume Langkah : : $124,5 \mathrm{cc}$

5) Perbandingan kompresi : 10,2:1

6) Sistem pengapian : DC - CDI

b. Premium diperoleh dari pembelian di SPBU Cibitung. Bioetanol yang digunakan mempunyai grade $98 \%$ yang digunakan untuk bahan bakar.

\section{Pelaksanaan Penelitian}

1. Mempersiapkan alat, bahan dan instrumen penelitian;

2. Melaksanakan tune up pada kendaraan agar berada pada kondisi yang optimal;

3. Memasang selang dari burret (gelas ukur) ke saluran masuk (intake) bahan bakar, kemudian isi dengan premium murni $\left(\mathrm{E}_{0}\right)$;

4. Menghidupkan blower untuk menjaga temperatur mesin;

5. Kendaraan dihidupkan dengan waktu \pm 3 menit, agar suhu kerja mesin mencapai optimal;

6. Menghidupkan alat emisi gas buang yang sudah diinstall pada kendaraan;

7. Melakukan pengukuran emisi gas buang sesuai prosedur penggunaan alat uji sebanyak dua kali, dengan komposisi campuran bahan bakar $\mathrm{E}_{0}, \mathrm{E}_{5}, \mathrm{E}_{10}, \mathrm{E}_{15}$ dan $\mathrm{E}_{20}$;

8. Mencetak hasil pengukuran, dan menonaktifkan alat uji. 


\section{HASIL DAN PEMBAHASAN}

1. Hasil Pengujian Kandungan Emisi $\mathrm{CO}$ dalam \% volume

Dari hasil percobaan perbandingan campuran bahan bakar premium dan bioetanol, maka diperoleh tabel nilai kandungan emisi $\mathrm{CO}$, adalah sebagai berikut:

Tabel 1. Hasil Pengujian Kandungan Emisi CO dalam \% volume

\begin{tabular}{|c|c|c|c|c|c|}
\hline \multirow{2}{*}{ RPM } & \multicolumn{5}{|c|}{ Konsentrasi CO (\% vol) } \\
\cline { 2 - 6 } & E0 & E5 & E10 & E15 & E20 \\
\hline idle & 6.45 & 6.38 & 5.96 & 5.29 & 4.57 \\
\hline 1500 & 6.33 & 5.92 & 5.61 & 4.76 & 3.12 \\
\hline 2000 & 4.47 & 4.05 & 3.65 & 3.32 & 2.96 \\
\hline 2500 & 4.21 & 3.68 & 3.06 & 2.46 & 1.73 \\
\hline
\end{tabular}

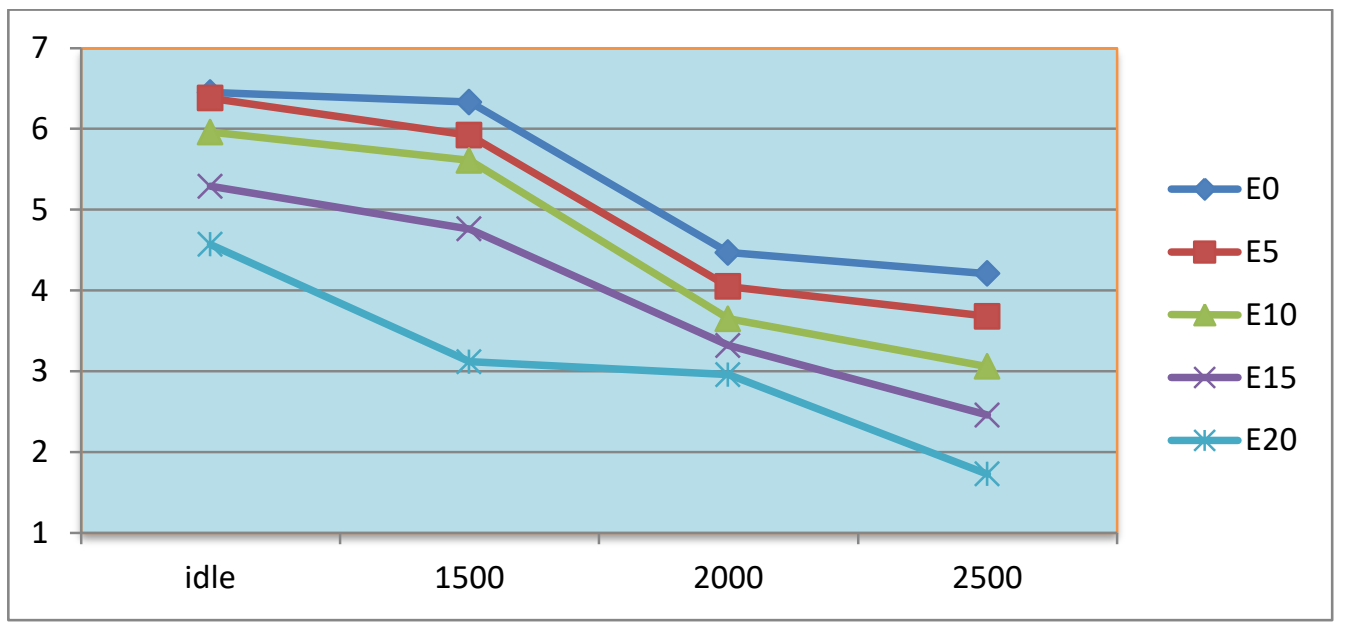

Gambar 2. Grafik Hasil Pengujian Kandungan Emisi CO dalam \% volume

Dengan memperhatikan grafik pada gambar 2, kadar CO pada setiap variasi bahan bakar mengalami penurunan seiring konsentrasi bioetanol dan putaran mesin yang semakin tinggi. Pada putaran mesin 1500, bahan bakar $\mathrm{E}_{0}$ hingga $\mathrm{E}_{20}$ terhitung tinggi, karena melebihi ambang batas sebesar 4,5\%vol. Kadar CO semakin menurun di bawah ambang batas pada putaran mesin 2000 sampai 2500. Penambahan bioetanol pada bahan bakar premium mampu 
memberikan dampak positif pada penurunan kadar $\mathrm{CO}$ yang terkandung dalam emisi gas buang. Kandungan oksigen pada bioetanol mampu membantu suplai oksigen yang dibutuhkan untuk pembakaran menjadi lebih terpenuhi, sehingga proses pembakaran mampu membakar unsur $\mathrm{C}$ dan mengubahnya bersama unsur $\mathrm{O}$ menjadi $\mathrm{CO}_{2}$ dan meminimalkan polusi.

2. Hasil Pengujian Kandungan Emisi $\mathrm{CO}_{2}$ dalam \% volume

Dari hasil percobaan perbandingan campuran bahan bakar premium dan bioetanol, maka diperoleh tabel nilai kandungan emisi $\mathrm{CO}_{2}$, adalah:

Tabel 2. Hasil Pengujian Kandungan Emisi $\mathrm{CO}_{2}$ dalam \% volume

\begin{tabular}{|c|c|c|c|c|c|}
\hline \multirow{2}{*}{ RPM } & \multicolumn{5}{|c|}{ Konsentrasi $\mathbf{C O}_{\mathbf{2}}(\mathbf{\%}$ vol) } \\
\cline { 2 - 6 } & E0 & E5 & E10 & E15 & E20 \\
\hline idle & 3.74 & 3.93 & 4.32 & 4.74 & 4.89 \\
\hline 1500 & 4.41 & 4.72 & 5.09 & 5.38 & 5.16 \\
\hline 2000 & 6.05 & 6.72 & 7.31 & 7.37 & 7.41 \\
\hline 2500 & 6.91 & 7.82 & 7.96 & 8.06 & 8.22 \\
\hline
\end{tabular}

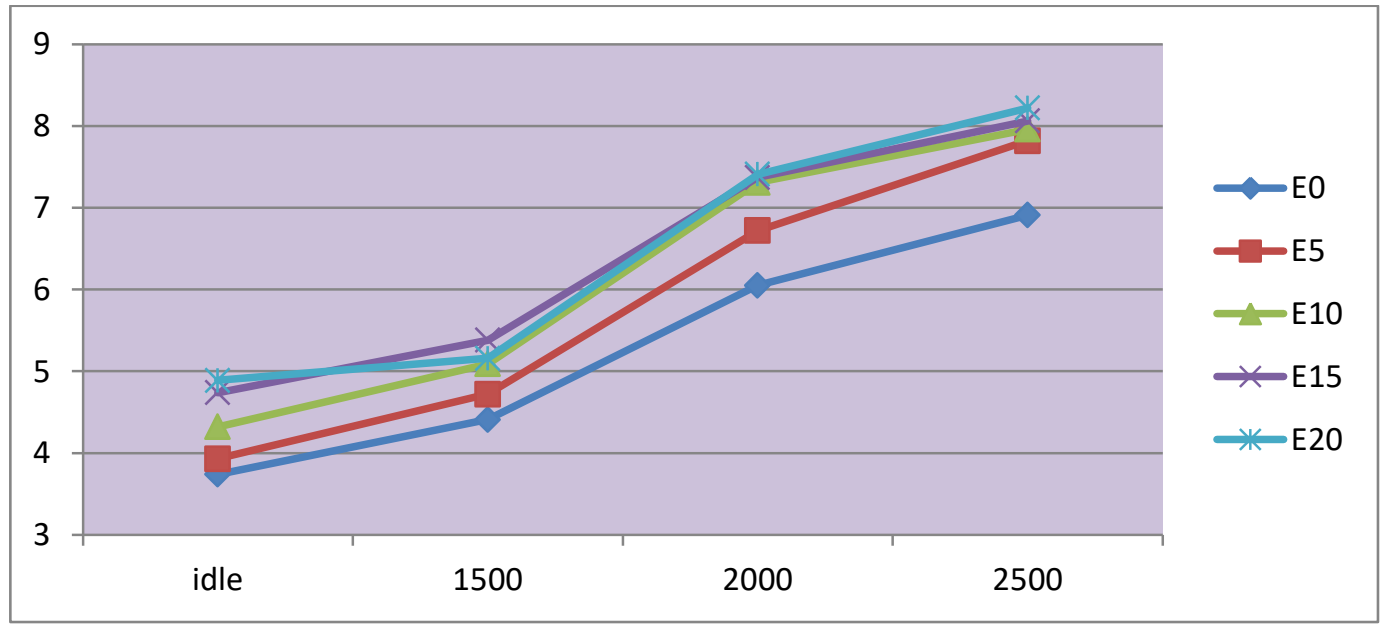

Gambar 3. Grafik Hasil Pengujian Kandungan Emisi $\mathrm{CO}_{2}$ dalam \% volume

Grafik pada gambar 3 menunjukkan besarnya kadar $\mathrm{CO}_{2}$ yang terkandung dalam emisi gas buang yang dihasilkan oleh setiap variasi bahan bakar pada setiap putaran. Kadar $\mathrm{CO}_{2}$ pada setiap variasi bahan bakar mengalami peningkatan seiring konsentrasi bioetanol dan putaran mesin yang semakin 
tinggi. Pada putaran mesin 1500, bahan bakar $\mathrm{E}_{0}$ hingga $\mathrm{E}_{20}$ terhitung rendah. Meningkat pada putaran mesin 2000 sampai 2500, kadar $\mathrm{CO}_{2}$ semakin meningkat. Rendahnya kadar $\mathrm{CO}_{2}$ pada putaran mesin 1500 dimungkinkan karena pada putaran rendah sudut pengapian cenderung mundur, sehingga berakibat pembakaran terlambat. Unsur yang terkandung dalam bahan bakar akan terbakar melalui pembakaran yang dihasilkan oleh bunga api busi.

3. Hasil Pengujian Kandungan Emisi HC dalam ppm volume

Dari hasil percobaan perbandingan campuran bahan bakar premium dan bioetanol, maka diperoleh tabel nilai kandungan emisi HC, sebagai berikut:

Tabel 3. Hasil Pengujian Kandungan Emisi $\mathrm{CO}_{2}$ dalam \% volume

\begin{tabular}{|c|c|c|c|c|c|}
\hline \multirow{2}{*}{ RPM } & \multicolumn{5}{|c|}{ Konsentrasi HC (ppm vol) } \\
\cline { 2 - 6 } & E0 & E5 & E10 & E15 & E20 \\
\hline idle & 1426 & 1173 & 946 & 1024 & 972 \\
\hline 1500 & 1238 & 981.5 & 796 & 851.5 & 834.5 \\
\hline 2000 & 365.5 & 305 & 241 & 287.5 & 307 \\
\hline 2500 & 207.5 & 148 & 85 & 92 & 145.5 \\
\hline
\end{tabular}

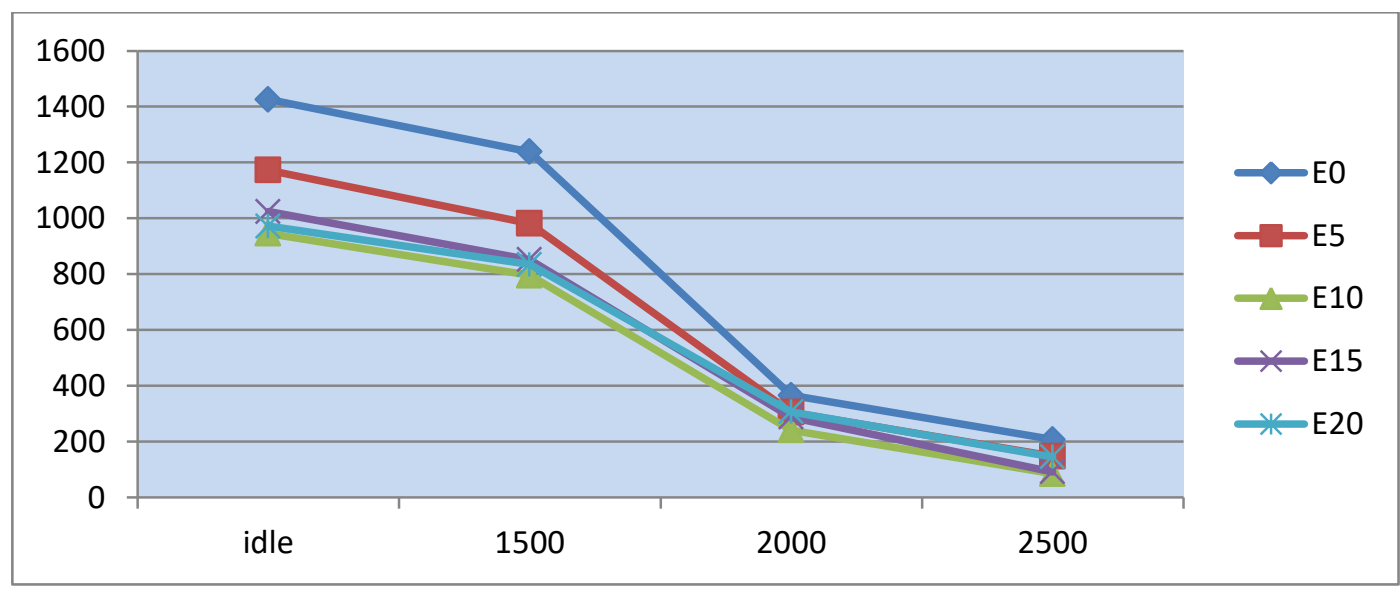

Gambar 4. Grafik Hasil Pengujian Kandungan Emisi HC dalam ppm volume

Pada gambar 4 menunjukkan besarnya kadar HC yang terkandung dalam emisi gas buang yang dihasilkan oleh setiap variasi bahan bakar pada setiap putaran. Kandungan HC pada putaran mesin 1500 yang terkandung dalam 
emisi melonjak sangat tinggi daripada putaran mesin 2000 hingga 2500 walaupun sudah berada di bawah ambang batas. Hal ini dimungkinkan karena pada putaran rendah, saat pengapian cenderung dimundurkan, sehingga berakibat pembakaran terlambat. Penggunaan bahan bakar $E_{15}$ hingga $E_{20}$, menghasilkan $\mathrm{HC}$ yang lebih tinggi dari $\mathrm{E}_{10}$. Hal ini dikarenakan pada campuran tersebut bahan bakar lebih sulit terbakar karena nilai kalor yang semakin rendah, sehingga sebagian bahan bakar yang tidak terbakar ikut keluar mengakibatkan HC meningkat pada variasi bahan bakar tersebut.

4. Hasil Pengujian Nilai Lambda $(\lambda)$

Dari hasil percobaan perbandingan campuran bahan bakar premium dan bioetanol, maka diperoleh tabel nilai Lambda $(\lambda)$, adalah sebagai berikut:

Tabel 4. Hasil Pengujian Nilai Lambda $(\lambda)$

\begin{tabular}{|c|c|c|c|c|c|}
\hline \multirow{2}{*}{ RPM } & \multicolumn{5}{|c|}{ Nilai Lambda } \\
\cline { 2 - 6 } & E0 & E5 & E10 & E15 & E20 \\
\hline idle & 1.17 & 1.21 & 1.25 & 1.32 & 1.56 \\
\hline 1500 & 1.15 & 1.17 & 1.22 & 1.27 & 1.43 \\
\hline 2000 & 1.12 & 1.13 & 1.21 & 1.24 & 1.32 \\
\hline 2500 & 1.11 & 1.11 & 1.18 & 1.19 & 1.28 \\
\hline
\end{tabular}

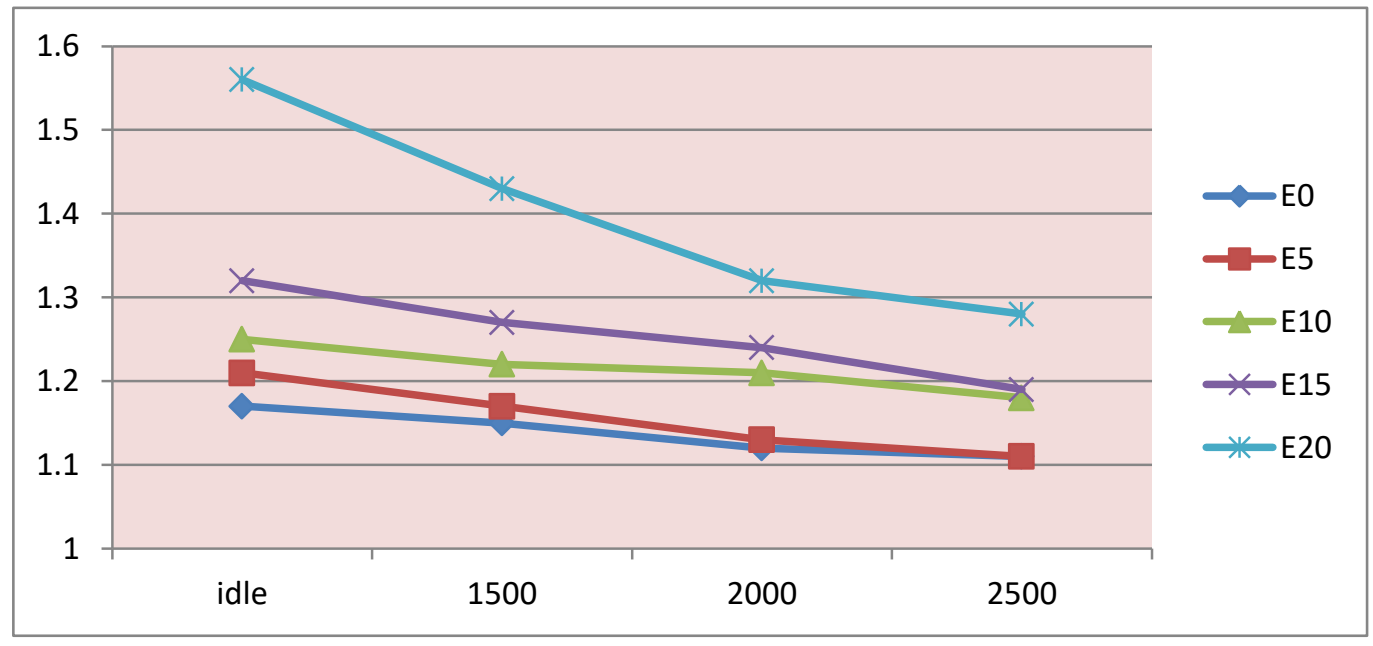

Gambar 5. Grafik Hasil Pengujian Nilai Lambda $(\lambda)$ 
Grafik pada gambar 5 menunjukkan besarnya nilai lambda yang dihasilkan oleh setiap variasi bahan bakar pada setiap putaran. Nilai lambda mengalami peningkatan di setiap variasi bahan bakar, namun semakin tinggi putaran mesin di setiap variasi bahan bakar, nilai lambda semakin menurun. Hal ini disebabkan oleh viskositas bahan bakar menurun, karena putaran mesin yang semakin tinggi, menyebabkan suhu mesin meningkat pula. Viskositas yang menurun menyebabkan bahan bakar mudah dikabutkan, sehingga campuran dan lambda menjadi lebih ideal pada putaran yang lebih tinggi

\section{DAFTAR PUSTAKA}

Arismunandar, W., 2002, Motor Bakar Torak, Edisi 5, ITB, Bandung.

Arends, BPM, Berenschot, H.,1980, (Alih Bahasa), Motor Bensin, PT. Erlangga, Jakarta.

Heywood, JB., 1988, Internal Combustion Engine Fundamentals, McGraw-Hill, Inc., USA.

Anonim, Manual Book Sepeda Motor Honda Vario, Astra Honda Motor, 2011.

Edward F. Obert, Internal Combustion Engines and Air Pollution, Harper \& Row, Publishers, Inc, 1973.

Erliza Hambali, Siti Mujdalipah, Armansyah Halomoan Tambunan, Abdul Waries Pattiwiri, dan Roy Hendroko. 2007. Teknologi Bioenergi. Jakarta: Agromedia Pustaka.

Kusminingrum Nanny dan G. Gunawan. 2008. Polusi Udara Akibat Aktivitas Kendaraan Bermotor di Jalan Perkotaan Pulau Jawa dan Bali.Bandung : Puslitbang Jalan dan Jembatan.

Michael J Moran dan Howard Shapiro, TermodinamikaTeknik 1, Erlangga.

PT. Astra Daihatsu Motor Training Center, Diktat VVT-i, Jakarta, 2008. 
Pulkrabek Willard W, Engineering Fundamentals of The Internal Combustion Engine, Prentice Hall, New Jersey.

Sugiyono. 2009. Metode Penelitian Kuantitatif Kualitatif dan R\&D. Bandung: Alfabeta.

Syahrani, A. 2006. Analisa Kinerja Mesin Bensin Berdasarkan Hasil Uji Emisi. Jurnal SMARTek.

Soedomo, Moestikahadi, Pencemaran Udara, Penerbit ITB, Bandung, 2001.

Saeful Rokhim, ST, MT dan team PPPTK (Pusat Pengembangan dan Pemberdayaan Pendidik Dan Tenaga Kependidikan Bidang Otomotif \& Elektronika Malang) - VEDC (Vocational Education Development Center), Modul Dasar Motor, Malang, 2011.

Yayan Sunarya. 2010. Kimia Dasar 1. Bandung: Yrama Widya. 